\title{
Towards supporting scholarship in research by clinical pharmacy faculty
}

\author{
A. Simon PICKARD.
}

\begin{abstract}
${ }^{*}$
Objective: The objective of this study was to assess the need for research support, faculty development, and topics of interest to clinical track pharmacy faculty that would facilitate scholarship in research. Methods: A cross-sectional survey of pharmacy practice-based faculty at University of Illinois at Chicago (UIC) completed via the web in November 2005.

Results: Of 39 clinical track faculty respondents (48\% response rate), $100 \%$ indicated they were interested in being co-investigator or $77 \%$ lead investigator on a research grant proposal. The majority of respondents expressed "a lot" or "extreme" interest in receiving methodological guidance and administrative support in order to pursue research interests. The greatest interest in research support services related to sample size calculations, selection of appropriate statistical tests, grant writing, and writing for journals. Barriers to research cited by faculty included lack of confidence in ability, the need for balancing responsibilities, and reward for efforts. Suggestions included the creation of specific research interest groups, research seminars, formal mentoring and statistical support services.

Conclusions: Clinical-track faculty are interested in research-related scholarship but typically lack the confidence or skills to lead research. While this study was limited to UIC clinical faculty, UIC faculty are attracted from Colleges of Pharmacy across North America and it is notable that such barriers can be quickly identified using a brief web-based survey in order to inform a plan that provides resources and support for research by clinical pharmacy faculty.
\end{abstract}

Keywords: Research Support. Education, pharmacy. Faculty. United States.

\begin{abstract}
RESUMEN
Objetivo: El objetivo de este estudio fue evaluar la necesidad de apoyo a la investigación, desarrollo del profesorado y los puntos de interés para el profesorado clínico que facilitaría la enseñanza en investigación.

Métodos: Estudio transversal de una facultad basada en la práctica de la Universidad de Illinois en Chicago (UIC) a través de la Web en noviembre de 2005.

Resultados: De los 39 académicos clínicos respondentes (48\% tasa de respuesta), $100 \%$ indicó que estarían interesados en ser co-investigador o el $77 \%$ investigador principal en una solicitud de beca de investigación. La mayoría de los que respondieron expresó "mucho" o "extremo" interés en recibir guía metodológica y apoyo administrativo para conseguir los intereses investigadores. El mayor interés en servicios de apoyo se relacionó con los cálculos del tamaño de muestra, selección de los apropiados tests estadísticos, escritura de becas y escritura de artículos para revistas. Las barreras a la investigación citadas por los académicos incluyeron la falta de confianza en su capacidad, la necesidad de equilibrar las responsabilidades, y el premio por los esfuerzos. Las sugerencias incluyeron la creación de grupos específicos de investigación, seminarios de investigación, tutela formal y servicios de apoyo estadístico.

Conclusiones: Los académicos clínicos están interesados en enseñanza relacionada con la investigación, pero generalmente carecen de confianza o habilidades para liderar investigación. Mientras que este estudio se limitó a los académicos de la UIC; los académicos de UIC son llegados desde otros puntos de Norte América y es notorio que estas barreras pueden identificarse usando un breve cuestionario en la Web para informar a un plan que proporcione recursos y apoyo a la investigación para los académicos clínicos.
\end{abstract}

Palabras clave: Apoyo a la investigación. Farmacia, formación. Académicos. Estados Unidos.

\section{(English)}

\section{INTRODUCTION}

*A. Simon PICKARD, BScPharm, PhD. Assistant Professor, Departments of Pharmacy Practice and Pharmacy Administration. College of Pharmacy, University of Illinois at Chicago, Chicago, Illinois (USA).
Scholarship in research is a highly valued and often requisite expectation of clinical pharmacy faculty at academic institutions. Many pharmacy practice departments in Colleges of Pharmacy include 
scholarship in research in their mission statements. $^{1-5}$ Many clinical-track faculty are interested in being involved in research but perceive many challenges and barriers to conducting research.

The nature of these challenges can vary with the institution and individual. Given the nature of their position, clinical faculty members have clinical responsibilities in addition to teaching and service. Faculty may be hindered by limited training in research methods. Opportunities to pursue research collaborations may depend upon the supportiveness of a department towards building a collaborative environment between faculty within and across disciplines. Colleges and departments can also vary in their supportiveness of protected time for research.

At the University of Illinois at Chicago (UIC), scholarship in research is a stated part of the explicit mission of the College of Pharmacy as well as the Department of Pharmacy Practice. ${ }^{1,2}$ The aim of this study was to evaluate the feasibility of conducting a brief web-based survey that required minimal resources in an effort to better understand the research interests and support needs of clinicaltrack faculty. Specifically, the objective was to identify topics of interest and forms of research support that would assist clinical faculty in furthering their career goals.

Objective: To perform a timely needs-based assessment of research interests, resources and training that would inform a program intended to support research scholarship by clinical-track faculty.

\section{METHODS}

A cross-sectional survey of pharmacy practicebased clinical faculty at UIC was completed by selfreport via the web in November 2005. UIC Institutional Review Board approval was received for the study protocol (2005-0692). An initial email was circulated to 82 clinical-track faculty in the Department of Pharmacy Practice by the department chair. Clinical-track faculty refers to practitioner educators who are not tenure-track and typically devote $50-70 \%$ effort to clinical practice and $30-40 \%$ teaching / experiential training. Promotion is possible but not mandatory, and scholarship in research can help an application for promotion (e.g. to clinical associate professor). Clinical-track faculty members were sent two weekly reminders requesting survey completion by the department chair.

The survey was initially developed based on perceived issues raised during a strategic retreat held in May 2005, and a departmental research forum in September 2005. Survey content and format was reviewed by 4 faculty members in Pharmacy Practice, then refined based upon feedback and piloting of the questionnaire. The questionnaire asked faculty to indicate their level of interest (none, a bit, a lot, extremely) in several pharmacy-related topics (pharmacokinetics, pharmacogenomics, and drug treatment outcomes) as well as their perceived need for support related to study design, analysis, data management, development of research questions/hypotheses, sample size calculations, IRB preparation, awareness of funding opportunities, grant writing, grant management and writing for journals. The final version of the questionnaire was formatted and adapted for web-based completion through a website maintained by Pharmacy Practice. Information technology staff in the department enabled tracking of respondents through assignment of a unique computer identification number related to their email address to ensure the questionnaire was completed only once by each respondent.

\section{RESULTS}

Of 39 clinical-track faculty respondents $(48 \%$ response rate), $87 \%$ completed residency training and $18 \%$ completed fellowship training. Almost all faculty felt that clinical faculty should be involved in research $(97 \%)$, and $69 \%$ supported the notion that clinical faculty should be required to conduct scholarly activities such as publish at least one paper annually. All respondents indicated they would be interested in being a co-investigator and $77 \%$ were interested in being lead investigator on a research project. In the past 2 years, the median average number of publications was 1 (range 0 to $21)$. Less than $50 \%(18 / 39)$ were satisfied with current scholarly productivity.

The majority of respondents expressed "a lot" or "extreme" interest in support and training in areas related to the more technical aspects of research, such as data management and analysis, with the strongest endorsement for items relating to sample size calculations and selection of appropriate statistical tests (Table 1). Items related to acquiring research funding, grant management, and research dissemination were also endorsed with "a lot" or "extreme(ly)" interested, particularly with respect to grant writing, and writing for journals (Table 1). Clinical-track faculty expressed "a lot" or "extreme" interest in the following topics: $87 \%$ drug treatment outcomes; $56 \%$ pharmacogenetics; $33 \%$ pharmacokinetics $(p<0.001)$.

A final question on the survey was an open-ended comments section. The general tenor of respondent research support needs may be gleaned from the range of comments received. These included "I need help with navigation of structure of the university research system"; "faculty mentorship is needed to assist in the pursuit of promotion"; "need to developed mentoring system at all levels (junior, intermediate, etc)"; "need to provide more focus and support for research efforts initiated by clinical faculty". Suggestions included the creation of interest groups for faculty to collaborate on publishing papers on similar interests, give clinical track faculty protected time if scholarly productivity is desired/expected, provide statistical support including group licenses for statistical software and tutoring on how to use and interpret output, and advice on how to conduct survey research. 


\begin{tabular}{|c|c|c|c|c|}
\hline \multirow[b]{2}{*}{ Content Area } & \multicolumn{4}{|c|}{$\begin{array}{c}\text { Level of interest/relevance } \\
\text { (in further training and guidance) }\end{array}$} \\
\hline & $\begin{array}{l}\text { No interest } \\
(n, \%)\end{array}$ & $\begin{array}{l}\text { A little bit of interest } \\
\qquad(\mathrm{n}, \%)\end{array}$ & $\begin{array}{l}\text { A lot of interest } \\
(n, \%)\end{array}$ & $\begin{array}{c}\text { Extremely } \\
\text { interested } \\
(\mathrm{n}, \%)\end{array}$ \\
\hline \multicolumn{5}{|l|}{ Conducting Research } \\
\hline $\begin{array}{l}\text { Development of an appropriate research } \\
\text { question \& testable hypotheses }\end{array}$ & $1(3 \%)$ & $12(31 \%)$ & $16(41 \%)$ & $10(26 \%)$ \\
\hline Selection of an appropriate study design & $1(3 \%)$ & $6(15 \%)$ & $23(59 \%)$ & $9(23 \%)$ \\
\hline Performing sample size calculations & $1(3 \%)$ & $4(10 \%)$ & $17(44 \%)$ & $17(44 \%)$ \\
\hline Basics of data management & $1(3 \%)$ & $2(5 \%)$ & $18(46 \%)$ & $18(46 \%)$ \\
\hline Selecting appropriate statistical tests & $1(3 \%)$ & $1(3 \%)$ & $13(33 \%)$ & $24(62 \%)$ \\
\hline \multicolumn{5}{|l|}{ Research Support and Dissemination } \\
\hline Guidance on IRB preparation/issues/processes & $4(10 \%)$ & $10(26 \%)$ & $13(33 \%)$ & $12(31 \%)$ \\
\hline Receiving updates on funding opportunities & $0(0 \%)$ & $10(26 \%)$ & $17(44 \%)$ & $12(31 \%)$ \\
\hline Administrative aspects of grant management & $1(3 \%)$ & $9(24 \%)$ & $15(39 \%)$ & $13(34 \%)$ \\
\hline How to write grant proposals/study protocols & $2(5 \%)$ & $6(15 \%)$ & $16(41 \%)$ & $15(38 \%)$ \\
\hline Guidance on writing for peer-reviewed journals & $0(0 \%)$ & $10(26 \%)$ & $12(31 \%)$ & $17(44 \%)$ \\
\hline \multicolumn{5}{|l|}{ Topics for further learning } \\
\hline Pharmacokinetics & $6(15 \%)$ & $20(51 \%)$ & $10(26 \%)$ & $3(8 \%)$ \\
\hline Pharmacogenomics & $2(5 \%)$ & $15(38 \%)$ & $15(38 \%)$ & $7(18 \%)$ \\
\hline Outcomes of drug treatment & $0(0 \%)$ & $5(13 \%)$ & $22(56 \%)$ & $12(31 \%)$ \\
\hline
\end{tabular}

\section{DISCUSSION}

The survey was conceptualized and conducted in less than 1 month, which demonstrated that a webbased approach to guiding departmental program development based on input from a large department of clinical faculty could be accomplished in a relatively short timeframe. The survey indicated the majority of clinical faculty were interested in being involved in research and publishing in peer reviewed journals but only a small subset of faculty accomplish this goal based on number of publications per year. Faculty cited a need for both methodological and administrative (e.g. grant management skills) support. Open-ended comments indicated academically based clinical faculty can be frustrated by competing responsibilities that marginalize their ability to conduct scholarly research.

The majority of clinical track faculty expressed a strong need for support and instruction in most aspects of conducting well-designed research studies, as well as guidance on grant writing, grant management, and dissemination of research (i.e. writing for peer-reviewed journals). Open-ended responses could be grouped into several common themes, including lack of confidence in ability, need for assistance in navigating the grant submission and research system, a difficulty in balancing responsibilities, interest in creation of specific research groups, and a need for greater mentorship and statistical support.

One of the most effective approaches to individualized faculty support and guidance in research may be mentorship. The need for effective mentorship has been recognized in colleges of medicine $^{6,7}$ as well as pharmacy. ${ }^{8,9}$ In 1993, the American Association of Colleges of Pharmacy (AACP) Commission to Implement Change in Pharmaceutical Education recommended that each school/college of pharmacy (COP) have a faculty development plan. This plan recommended that established faculty members mentor new faculty, especially with regards to scholarship expectations for promotion and achieving tenure and that COPs also develop a quality assurance system for clinical fellowships and graduate programs. ${ }^{10}$ Despite these recommendations more than 10 years ago, a recent study of administrators and deans in U.S. pharmacy schools/colleges found that there continues to be a need for a visible commitment to faculty development and mentoring in academic pharmacy. ${ }^{11}$

From this survey, a number of initiatives to support research by clinical faculty were identified. These initiatives included providing a guidebook to conducting research and resources posted on a departmental website; providing coordinated promotion of seminars being conducting in various research areas relevant to clinical faculty; circulation of funding opportunities via email; rewarding publications/proposal submissions with protected time for research; mentorship pairing with tenuretrack faculty; providing study protocol and grant development workshops; and initiating special interest research groups. Addressing these issues through a structured approach to research support and mentorship may pay substantial dividends in terms of the untapped potential for scholarly research by clinical track faculty. Future research could evaluate the impact of a research support infrastructure by conducting a follow-up survey of the clinical track faculty, potentially assessing the within-subject impact by tracking the email-based unique computer identifiers of faculty.

UIC has a large group of clinical faculty who received extensive training in pharmacy throughout the United States and the world. While the generalizability of this survey is limited in that it was only distributed to clinical track faculty at UIC, the issues identified through this survey may resonate with many clinical faculty. Some of the recommendations identified in this survey may help to promote research scholarship among clinical 
faculty throughout Colleges of Pharmacy. Alternatively, Colleges of Pharmacy may wish to conduct their own brief web-based survey to better understand the research support needs of clinical faculty. This may ultimately enhance career satisfaction among faculty while simultaneously raising the profile of research scholarship conducted by clinical faculty at their institution.

\section{ACKNOWLEDGEMENTS}

The author is grateful to Melquaides Manuel, Eileen Banaticla, and Glenda Genio-Terrado for assistance in implementing the survey; Mike Koronkowski, Pharm.D, Marieke Schoen, Pharm.D, for reviewing survey content; and Jerry L. Bauman, Pharm.D., FCCP, for facilitating this research and reviewing an earlier draft of the manuscript.

\section{References}

1. College Vision and Mission, University of Illinois at Chicago College of Pharmacy, http://www.uic.edu/pharmacy/content/about/frame_vision.htm, (Accessed December 1, 2005).

2. Mission Statement, Department of Pharmacy Practice, University of Illinois College of Pharmacy. http://uic.edu/pharmacy/depts/pmpr/missionframe.htm, (Accessed December 1, 2005).

3. Mission Statement and Vision Statement, University of Southern California School of Pharmacy. http://www.usc.edu/schools/pharmacy/about/mission.html, (Accessed December 1, 2005).

4. Pharmacy Practice Department Information. University of Kansas. http://www.pharm.ku.edu/contentm/gen/school_of_pharmacy_generated_ns_pages/Pharmacy_Practice_m62.html, (Accessed December 1, 2005).

5. Department of Pharmacy Practice, Purdue University. http://www.phpr.purdue.edu, (Accessed December 1, 2005).

6. Curtis P, Dickinson P, Steiner J, Lanphear B, Vu K. Building capacity for research in family medicine: is the blueprint faulty? Fam Med 2003;35(2):124-30.

7. Fang D, Meyer RE. PhD faculty in clinical departments of U.S. medical schools, 1981-1999: their widening presence and roles in research. Acad Med 2003;78(2):167-76.

8. Popovich NG, Abel SR. The need for a broadened definition of faculty scholarship and creativity. Am J Pharm Educ 2002;66:59-65.

9. Kennedy RH, Gubbins PO, Luer M, Reddy IK, Light KE. Developing and sustaining a culture of scholarship. Am J Pharm Educ 2003.

10. Commission to Implement Change in Pharmaceutical Education. The responsibility of pharmaceutical education for scholarship in graduate education, fellowships, and postgraduate professional education and training. Am J Pharm Educ 1993;57:386-99.

11. MacKinnon GE. Administrator and dean perceptions toward faculty development in academic pharmacy. Am J Pharm Educ 2003;67(3)Article 97. 